\title{
STUDIES ON THE CIRCULATION IN PREGNANCY. I. THE VE- LOCITY OF BLOOD FLOW AND RELATED ASPECTS OF THE CIRCULATION IN NORMAL PREGNANT WOMEN ${ }^{1}$
}

\author{
BY MANDEL E. COHEN AND K. JEFFERSON THOMSON \\ (From the Department of Obstetrics, Harvard University Medical School and the Cardiac Clinic \\ and Research Laboratory, Boston Lying-in Hospital, Boston)
}

(Received for publication June 15, 1936)

It has long been known that pregnancy imposes a "burden" upon the maternal circulation. Gain in body weight $(1,2,3,4)$, anemia $(5,6,7)$, increased cardiac output $(8,9,10,11,12,13)$, increased oxygen consumption $(8,14,15,16,17)$, increased blood volume $(18,19,20)$, elevation in pulse rate $(11,21)$ and the addition of the placental circulation are all probable factors in the production of the increased load on the heart in pregnancy.

General studies on the circulation are being carried out at the Boston Lying-in Hospital in an attempt to understand the physiology of the circulation in pregnancy and to determine, if possible, the nature of this so-called "burden" on the circulation. It was hoped that such studies would lead to a practical, satisfactory method of predicting and diagnosing early heart failure in pregnant women with heart disease before the clinical signs of cardiac decompensation become evident.

This communication presents, in the main, studies on the circulation of a group of normal pregnant women, with particular emphasis on the velocity of blood flow. This aspect of the circulation in pregnancy has received little attention in contrast to its extensive study in non-pregnant individuals ( 22 to 37 inclusive).

The only two studies on the velocity of blood flow in pregnant women can be reviewed briefly. F. Klee (38) in 1924, studied the circulation time (which varies inversely with the velocity of blood flow), in pregnancy by the fluorescein method of Koch (37). He made single observations on 100 pregnant women in the last three months of pregnancy and found that whereas in normal nonpregnant controls the average circulation time was 20.8 seconds, in pregnant women there was a slow-

1 This is the first of a series of papers concerning various aspects of the circulation in pregnancy. ing to 25.2 seconds in primiparae and to $23.4 \mathrm{sec}$ onds in multiparae. The maximum slowing occurred in the eighth month.

W. Spitzer (39) in 1933, using the decholin (sodium dehydrocholate) method of Winternitz, Deutsch and Brüll (27), studied the velocity of blood flow in 27 normal pregnant women and in 29 abnormal ones. From single observations on each patient he found no change between normal pregnant women and normal non-pregnant controls (the circulation time, arm to tongue, for normal non-pregnant individuals varied between 8 to 14 seconds, no average given; for normal pregnant ones the variation was between 10 and 16 seconds, with an average of 14.3 seconds). There was some slowing of the circulation in 4 cases of toxemia of pregnancy $(25,16.5,26$ and 25 seconds), in 3 cases of eclampsia $(22,17$ and 17 seconds) and in 1 case of mitral stenosis (19 seconds). On the basis of these findings Spitzer suggested that this test might be used as an efficiency test for cardiac function in pregnant women with cardiac disease and as a test for the severity of the toxemias of pregnancy.

\section{PROCEDURE}

The subjects for this study were obtained from the prenatal clinics of the Boston Lying-in Hospital and only those who had no serious medical or obstetrical complication were included in the normal group. Observations were made, when possible, at monthly intervals throughout pregnancy; at 2 and 6 weeks postpartum and in some patients 7 weeks or longer after delivery. The number of observations on the same patient varied between 1 and 10 .

The following determinations were usually made at each visit: weight, arterial blood pressure, pulse and respiratory rates, circulation time (28) (arm to carotid, crude pulmonary and venous), 
vital capacity, subcostal angle, hemoglobin, hematocrit and, in some patients, venous pressure and basal metabolic rate. Seven foot $x$-rays of the heart and electrocardiograms were taken on some of the patients in this study. Basal metabolic rates were determined on the patients in whom there was any suspicion of thyroid dysfunction. Every patient at each visit received a careful physical examination of the heart, lungs, abdomen and extremities.

All patients were studied under basal conditions, i.e., fasting and resting. Determinations of venous pressure were preceded by at least $20 \mathrm{~min}$ utes rest in bed and measurements of the circulation time by at least 30 minutes rest in bed. Vital capacities were determined after the patient had been sitting upright for at least 30 minutes and with a 5 minute interval between each reading. The highest of at least 3 observations which checked within $50 \mathrm{cc}$. was taken as the value for that day. (Further details of the exact procedure used for determining the vital capacity will appear in a subsequent communication.)

\section{METHODS}

The arterial blood pressure was measured with a standard mercury sphygmomanometer; the venous blood pressure was determined by the direct venipuncture method of Moritz and von Tabora (40). Determinations of vital capacity were made with a simple calibrated water spirometer (Collins). Measurements of the circulation time were made according to the cyanide method of Robb and Weiss (28), which consists of the injection of sodium cyanide into a vein and measuring the time elapsing between its injection and the appearance of a characteristic respiratory response. The technique of determining the arm to carotid (referred to subsequently in this paper as the $A-C$ ), crude pulmonary (referred to subsequently as the pulmonary), and the venous circulation time, which was used throughout this study has been fully described in previous reports by Robb and Weiss $(28,29)$. In some instances the decholin method (which measures the arm to tongue circulation time), as modified by Gargill (34), was used in conjunction with the cyanide method.

The surface area was computed from height- weight tables based on the formula of DuBois and DuBois (41) for surface area. The subcostal angle, except where otherwise noted, was measured with a protractor; the determining points for the angle measured being the xyphoid process, and points $7 \mathrm{~cm}$. distant from it, on the border of each costal margin. Hemoglobin determinations were made with a Sahli hemoglobinometer calibrated so that 100 per cent represents 15.6 grams of hemoglobin per $100 \mathrm{cc}$. of blood. Hematocrit readings were made by the Wintrobe method (42). Edema was noted from either history or physical examination or both. Either subjective or objective evidence of shortness of breath was interpreted as dyspnea. The duration of gestation in weeks, which represents the time during pregnancy at which any given observation was made, has been calculated back from the actual date of delivery; the duration of a normal full term pregnancy being taken as 40 weeks. In those patients whose pregnancy was terminated at any point before term, the date of observation in terms of duration of pregnancy was calculated in the usual manner (Naegele's method) from the date of the last menstrual period.

\section{RESULTS}

Of 37 normal pregnant women studied (Table I), there are 20 primiparae, 10 secundiparae, 3 tertiparae, and 4 quadriparae. The average age of the group is 24.5 years; of the primiparae 22.9 years, of the secundiparae 24.8 years, of the tertiparae 28.3 years, of the quadriparae 28.5 years.

\section{Arm to carotid circulation time}

One hundred and forty-three determinations of the $\mathrm{A}-\mathrm{C}$ circulation time were made on 36 normal pregnant women; 100 observations ante partum and 43 postpartum (Figure 1 ). The $\mathrm{A}-\mathrm{C}$ circulation time varied between 10 and 24 seconds, ante partum, an average of 14.5 seconds; between 9 and 23 seconds, postpartum, an average of 14.9 seconds. The normal range in non-pregnant individuals by the cyanide method is from 9 to 21 seconds with an average of 15.6 seconds (28). The postpartum variation in the 7 th to 81 st week period was from 12 to 23 seconds, with an average time of 16.0 seconds which corresponds closely with the normal non-pregnant average of 


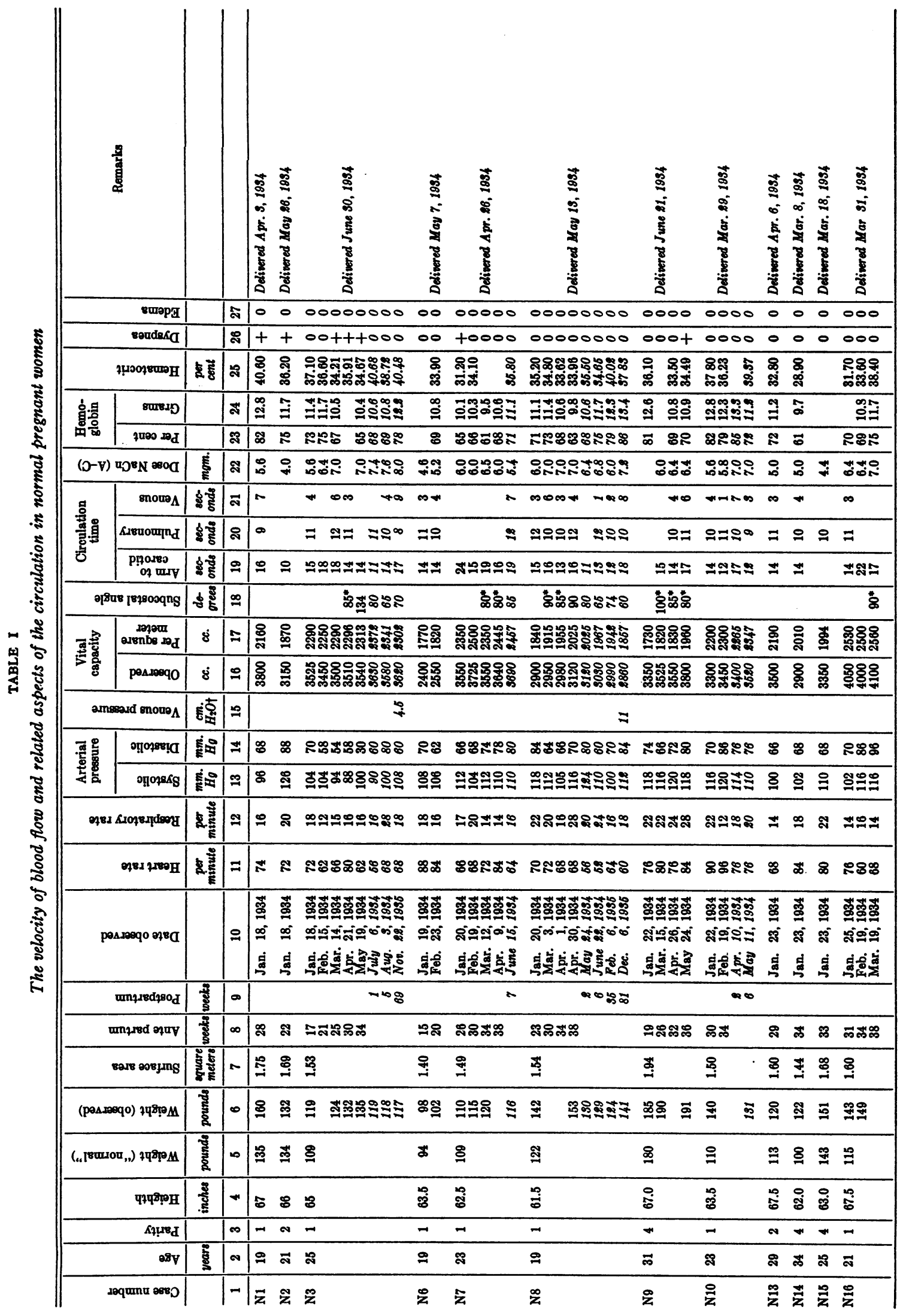




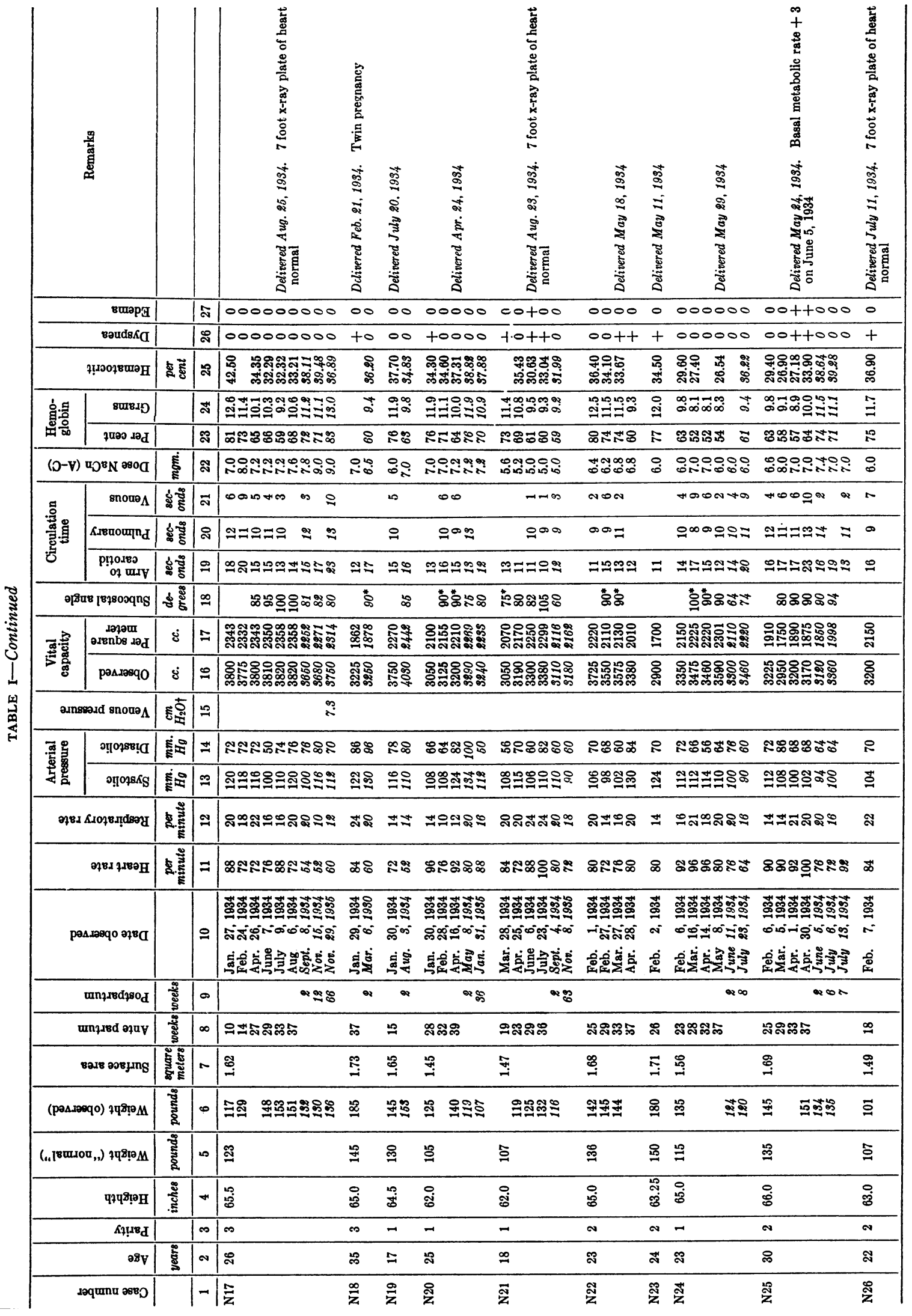




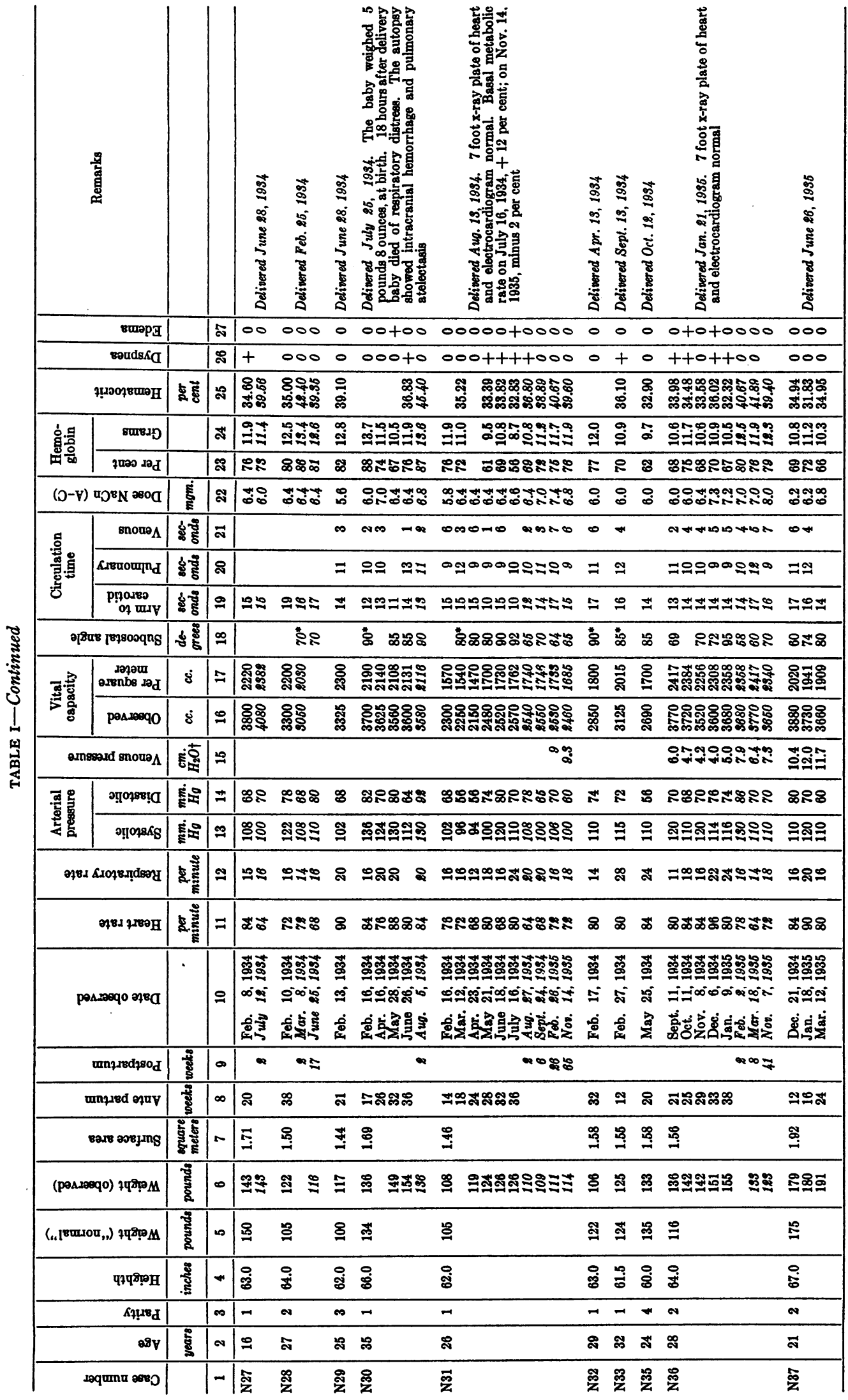




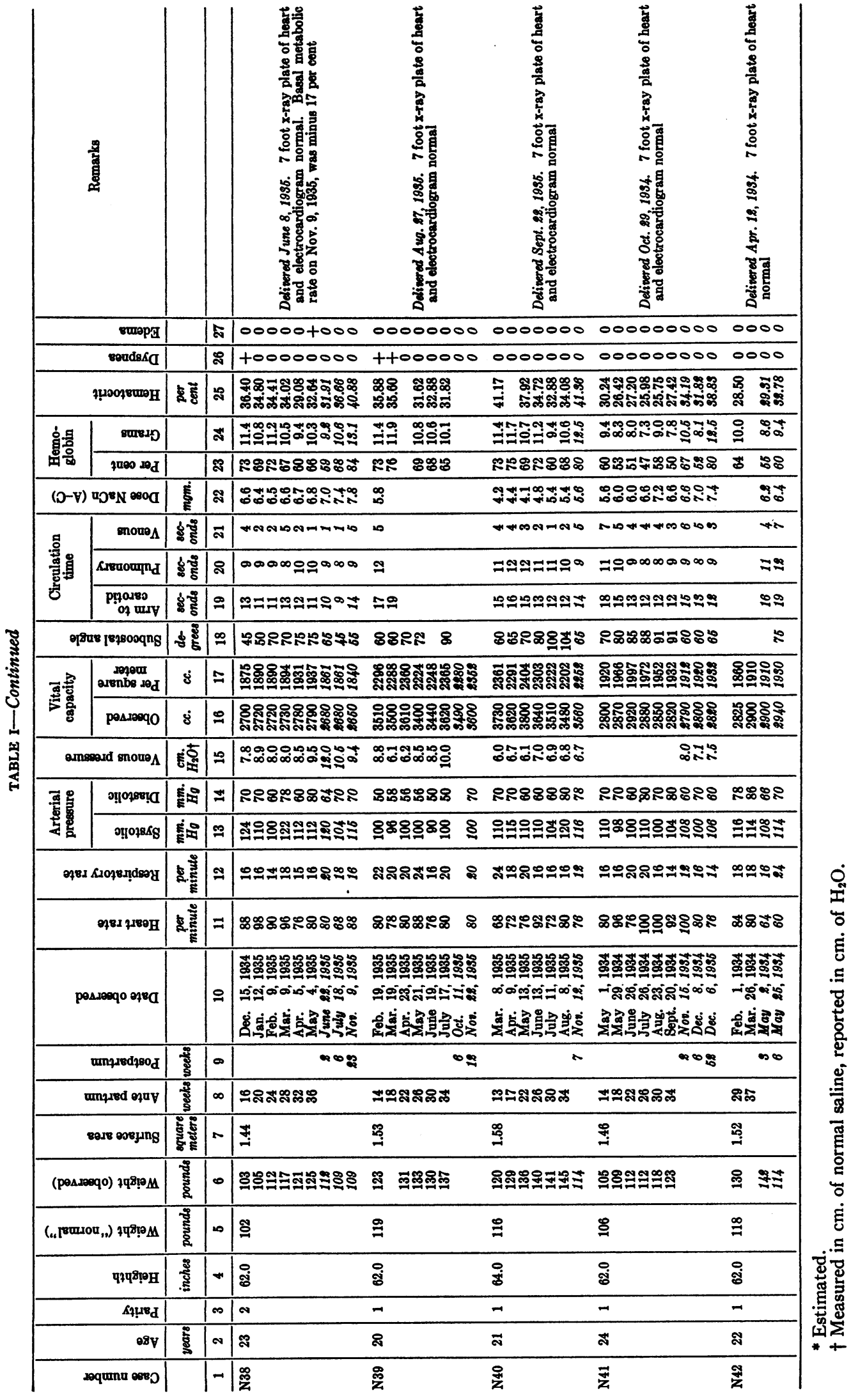




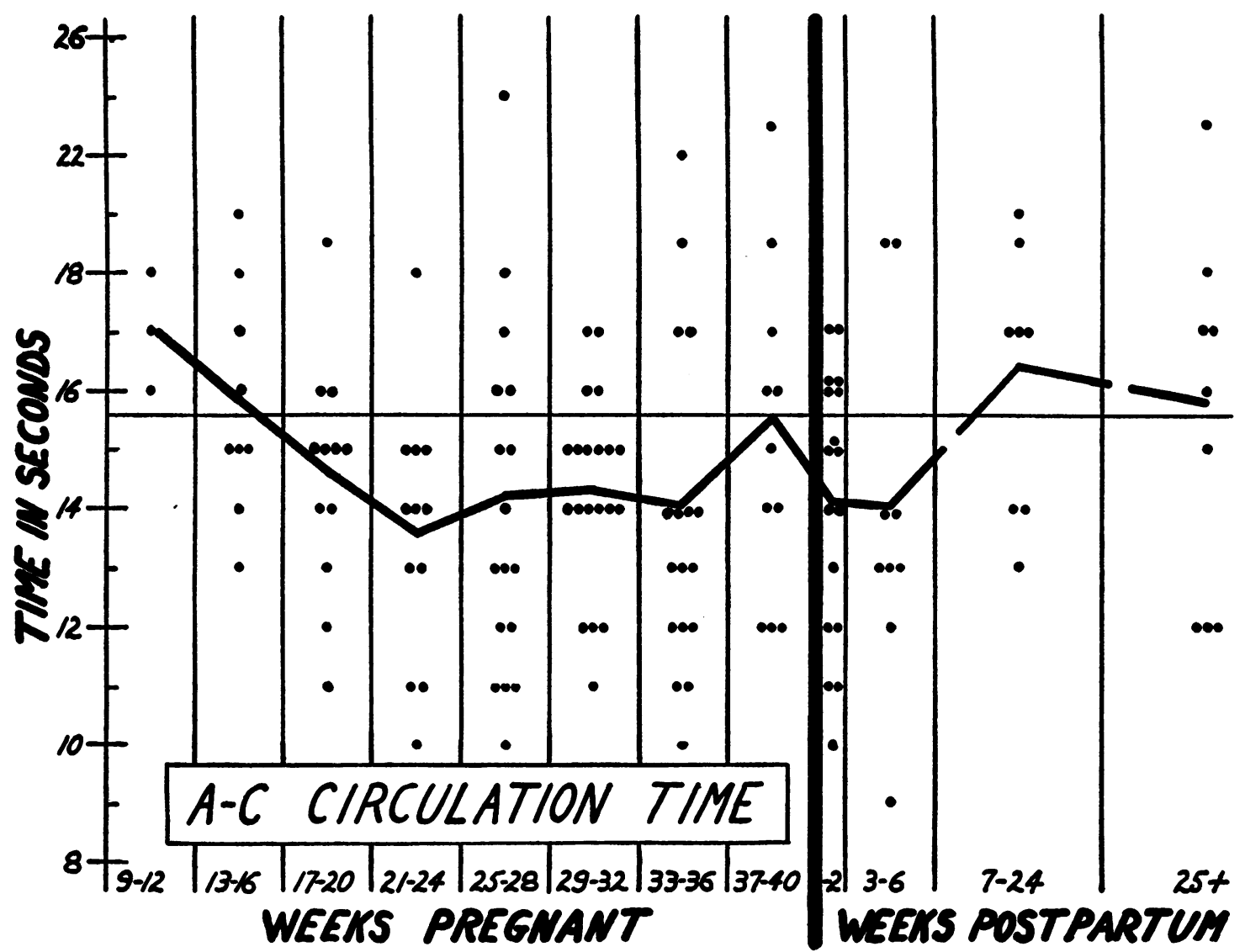

Fig. 1. The Arm to Carotid Circulation Time in Normal Pregnant Women.

The solid dots represent individual observations; the solid heavy line represents the average values. The horizontal black line represents the average normal non-pregnant $\mathrm{A}-\mathrm{C}$ circulation time. The heavy perpendicular line represents delivery and separates the ante and postpartum periods.

15.6 seconds. These late postpartum observations constitute a normal control group for this study.

The shortening of the circulation time indicated by the curve of average values (Table II) did not occur invariably or at every observation, although present in the majority of repeatedly studied cases. In a few instances there was prolongation, while occasionally no change could be detected.

TABLE II

The average A-C, pulmonary and venous circulation times; the average pulse rate, hemoglobin, hematocrit and viscosity of the blood at varying intervals during pregnancy and the puerperium

\begin{tabular}{|c|c|c|c|c|c|c|c|c|c|c|c|c|}
\hline & \multicolumn{8}{|c|}{ Weeks pregnant } & \multicolumn{4}{|c|}{ Weeks postpartum } \\
\hline & 9 to 12 & 13 to 16 & 17 to 20 & 21 to 24 & 25 to 28 & 29 to 32 & 33 to 36 & 37 to 40 & 1 to 2 & 3 to 6 & 7 to 24 & $25+$ \\
\hline 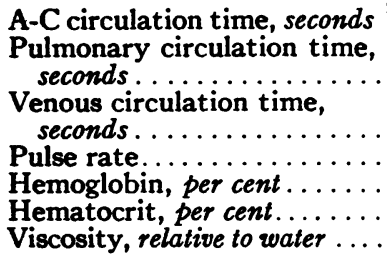 & \begin{tabular}{|c|}
17.0 \\
11.6 \\
5.3 \\
84.0 \\
73.3 \\
37.83 \\
4.685
\end{tabular} & \begin{tabular}{|c|}
15.9 \\
10.7 \\
5.2 \\
79.8 \\
72.0 \\
35.49 \\
4.456
\end{tabular} & \begin{tabular}{c|}
14.6 \\
10.4 \\
3.8 \\
81.8 \\
72.4 \\
34.21 \\
4.331
\end{tabular} & \begin{tabular}{|c|}
13.6 \\
10.4 \\
3.4 \\
77.4 \\
67.3 \\
33.95 \\
4.305
\end{tabular} & \begin{tabular}{|c|}
14.2 \\
9.7 \\
4.3 \\
82.1 \\
67.8 \\
33.47 \\
4.258
\end{tabular} & \begin{tabular}{|c|}
14.3 \\
10.0 \\
4.2 \\
79.8 \\
67.1 \\
32.93 \\
4.205
\end{tabular} & \begin{tabular}{c|}
14.0 \\
10.0 \\
3.0 \\
81.6 \\
64.6 \\
32.90 \\
4.202
\end{tabular} & \begin{tabular}{|c|}
15.5 \\
10.6 \\
5.4 \\
80.0 \\
67.7 \\
35.08 \\
4.416
\end{tabular} & $\begin{array}{c}14.1 \\
10.7 \\
3.6 \\
69.3 \\
69.6 \\
36.64 \\
4.569\end{array}$ & \begin{tabular}{|c|}
14.0 \\
10.1 \\
\\
3.6 \\
69.7 \\
69.5 \\
37.50 \\
4.753
\end{tabular} & \begin{tabular}{c|}
16.4 \\
10.6 \\
\\
5.2 \\
70.0 \\
74.8 \\
39.28 \\
4.827
\end{tabular} & $\begin{array}{c}15.8 \\
9.8 \\
6.5 \\
71.0 \\
78.4 \\
39.03 \\
4.803\end{array}$ \\
\hline
\end{tabular}


The ante and postpartum values fell within the normal non-pregnant range in all but 4 instances; 3 ante partum and 1 postpartum (Table I, Cases $\mathrm{N} 7, \mathrm{~N} 16, \mathrm{~N} 17$ and $\mathrm{N} 25$ ). In contrast to Klee's findings (38) the average circulation time for primiparae and multiparae in this group was essentially the same; for primiparae the average ante partum $\mathrm{A}-\mathrm{C}$ time was 14.6 seconds; for multiparae 14.4 seconds.

No obvious correlation existed between the A-C circulation time and pulse rate or hemoglobin content of the blood (Figures 2 and 3 ).

\section{Pulmonary circulation time}

One hundred and twelve determinations of the pulmonary circulation time were made on 34 normal pregnant women; 78 before and 34 after de- livery (Figure 4). The pulmonary circulation time varied between 9 and 13 seconds ante partum, an average of 10.7 seconds; the postpartum variation was from 8 to 14 seconds, an average of 10.3 seconds. The variation in the pulmonary circulation time by the cyanide method in normal non-pregnant individuals is from 7 to 14 seconds with an average of 10.6 seconds (28). All of the values in the normal pregnant group are within the normal non-pregnant range and the average of 10.7 seconds for all the ante partum observations corresponds closely with the average of the normal non-pregnant individuals of 10.6 seconds; the average for all the postpartum values is 10.3 seconds.

Here again there is a definite slight shortening of the average pulmonary circulation time during

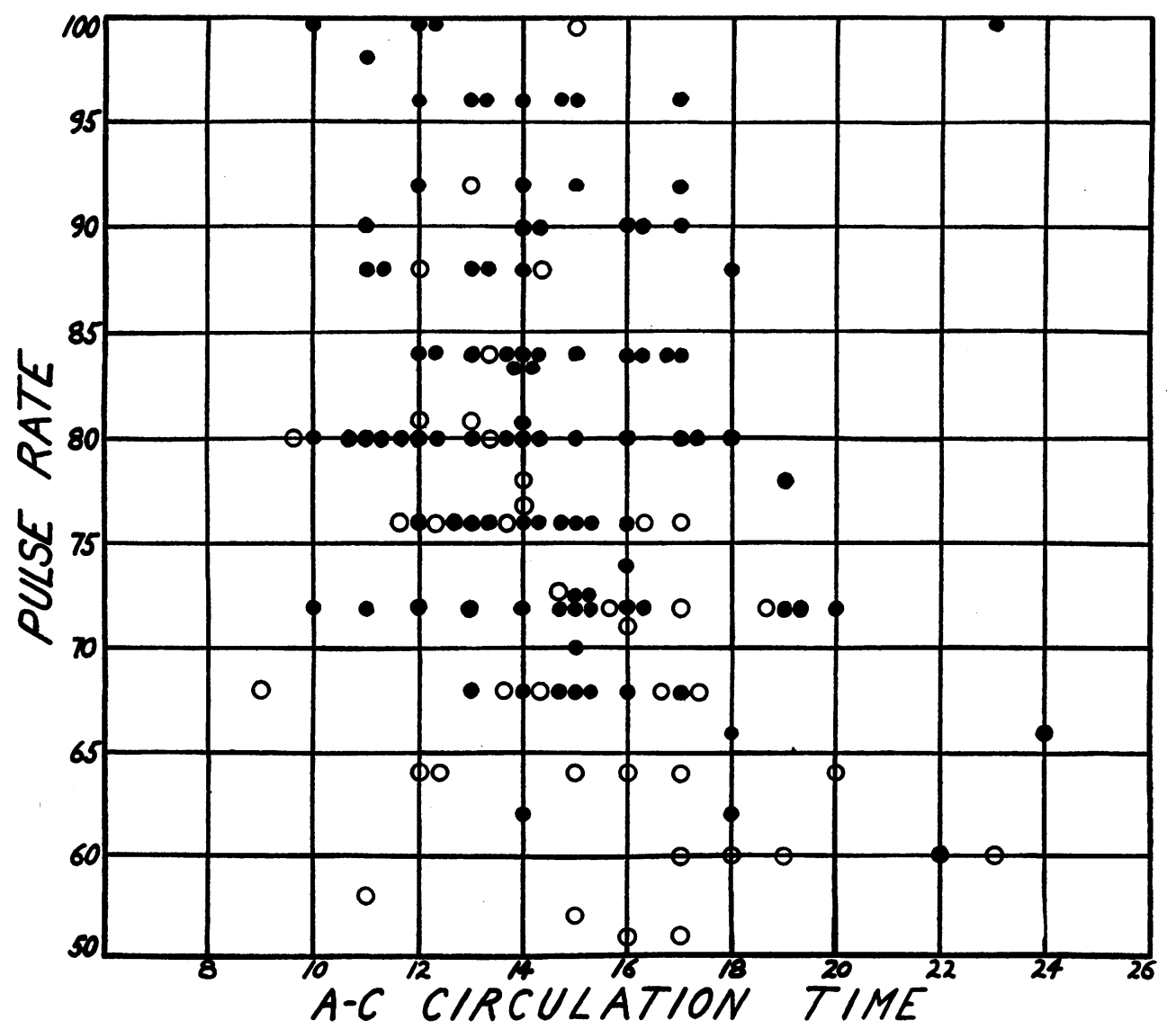

Fig. 2. The Relationship Between the Pulse Rate and the Arm to Carotid Circulation Time.

The solid dots represent individual ante partum observations, the circles represent individual postpartum observations. 


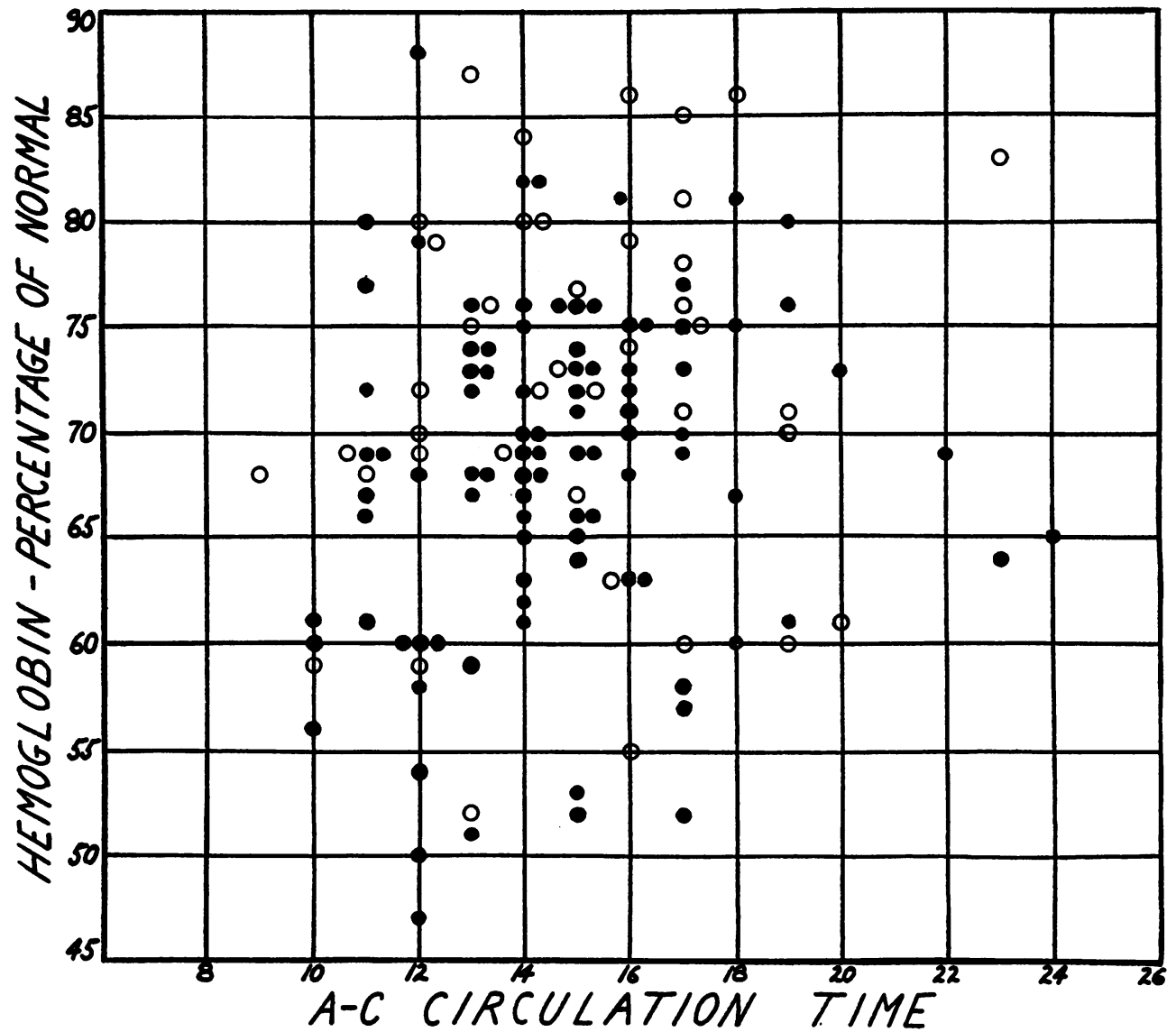

Fig. 3. The Relationship Between the Hemoglobin and the Arm to Carotid Circulation Time.

The solid dots represent individual ante partum observations, the circles represent individual postpartum observations.

pregnancy (Table II) although the change could not be detected in every case.

There was no obvious correlation between the pulmonary circulation time and the pulse rate and hemoglobin respectively (Figures 5 and 6).

\section{Venous circulation time}

The venous circulation time was calculated 108 times, 76 before, 32 after delivery, in 29 normal pregnant women. It varied between 1 and $9 \mathrm{sec}-$ onds ante partum (average 4.1 seconds). The postpartum variation was between 1 and $10 \mathrm{sec}-$ onds (average 4.5 seconds). The average venous time after the seventh week postpartum was 6.0 seconds. The normal non-pregnant variation in venous time by the cyanide method is from 1 to 9 seconds (average 4.5 seconds) (28). Since the average pulmonary circulation time showed relatively slight change throughout pregnancy and the puerperium (Figure 4) and because of the method of calculating the venous time, it is evident that the changes in the average venous time will vary as the A-C circulation time varies (Figure 7).

No correlation between either the pulse rate or hemoglobin and the venous circulation time could be demonstrated.

\section{Dose of sodium cyanide}

The effective dose of sodium cyanide for measuring the $\mathrm{A}-\mathrm{C}$ circulation time varied between 4.0 and $9.0 \mathrm{mgm}$. per patient (corresponding to $\mathbf{0 . 2}$ cc. to $0.45 \mathrm{cc}$. of a 2 per cent aqueous solution of 


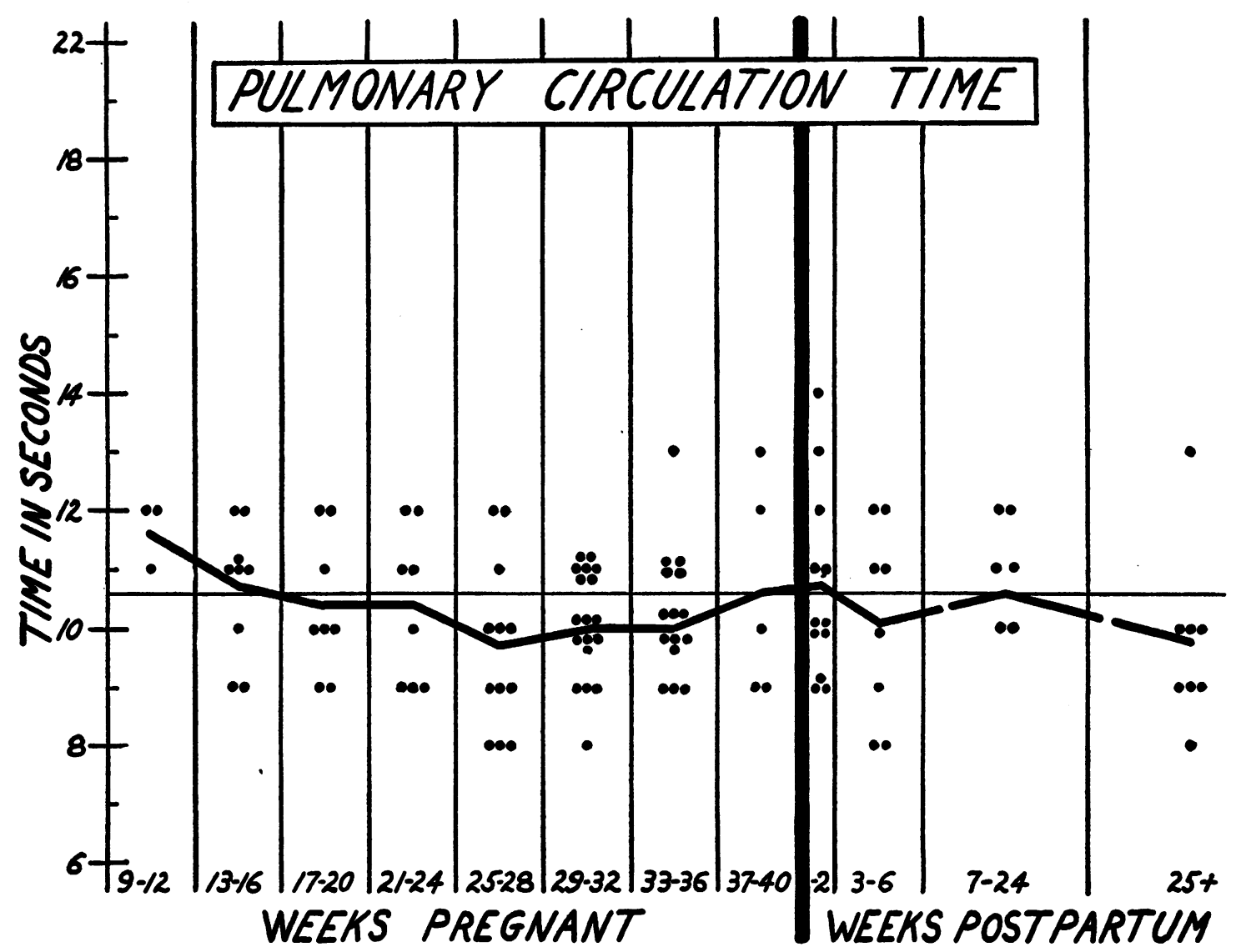

Fig. 4. The Pulmonary Circulation Time in Normal Pregnant Women.

The solid dots represent individual observations; the solid, heavy line represents the average values. The horizontal black line represents the average normal non-pregnant pulmonary circulation time. The heavy perpendicular line represents delivery and separates the ante and postpartum periods.

$\mathrm{NaCN}$ ). The dose per kilogram of body weight ante partum varied between 0.067 and $0.142 \mathrm{mgm}$. (average $0.102 \mathrm{mgm}$.). The average postpartum dose per kilogram of body weight was 0.127 mgm.; the smallest effective dose postpartum was $0.092 \mathrm{mgm}$. per kilo; the largest was $0.170 \mathrm{mgm}$. per kilo. The effective dose of sodium cyanide for non-pregnant normal individuals ranged from 5.0 to $10.0 \mathrm{mgm}$., or from 0.07 to $0.19 \mathrm{mgm}$. per kilogram of body weight, with an average dose of $7.0 \mathrm{mgm}$. or $0.11 \mathrm{mgm}$. per kilogram body weight (28). In 2 patients in this series the dose per kilogram body weight was less postpartum than ante partum; in 14 it was more and in 3 it remained the same. The effective dose of sodium cyanide required in determining the pulmonary circulation time was less in all instances than that required for determining the $\mathrm{A}-\mathrm{C}$ time, averaging about 75 per cent of the effective A-C dose. This is essentially what is found in non-pregnant normal subjects (28).

\section{Venous pressure}

Determinations of venous pressure were made on 10 patients, but in only 5 were they made ante partum (Cases N36, N37, N38, N39 and N40, Table I).

It varied between 4.0 and $12.0 \mathrm{~cm}$. of water ante partum and between 6.4 and $12.0 \mathrm{~cm}$. postpartum. The average ante partum was $7.9 \mathrm{~cm}$. of water, and postpartum $9.1 \mathrm{~cm}$. All of the values were within normal limits $(12.0 \mathrm{~cm}$. or less). In the one patient in whom it was consistently above $10 \mathrm{~cm}$. it should be noted that rather marked 


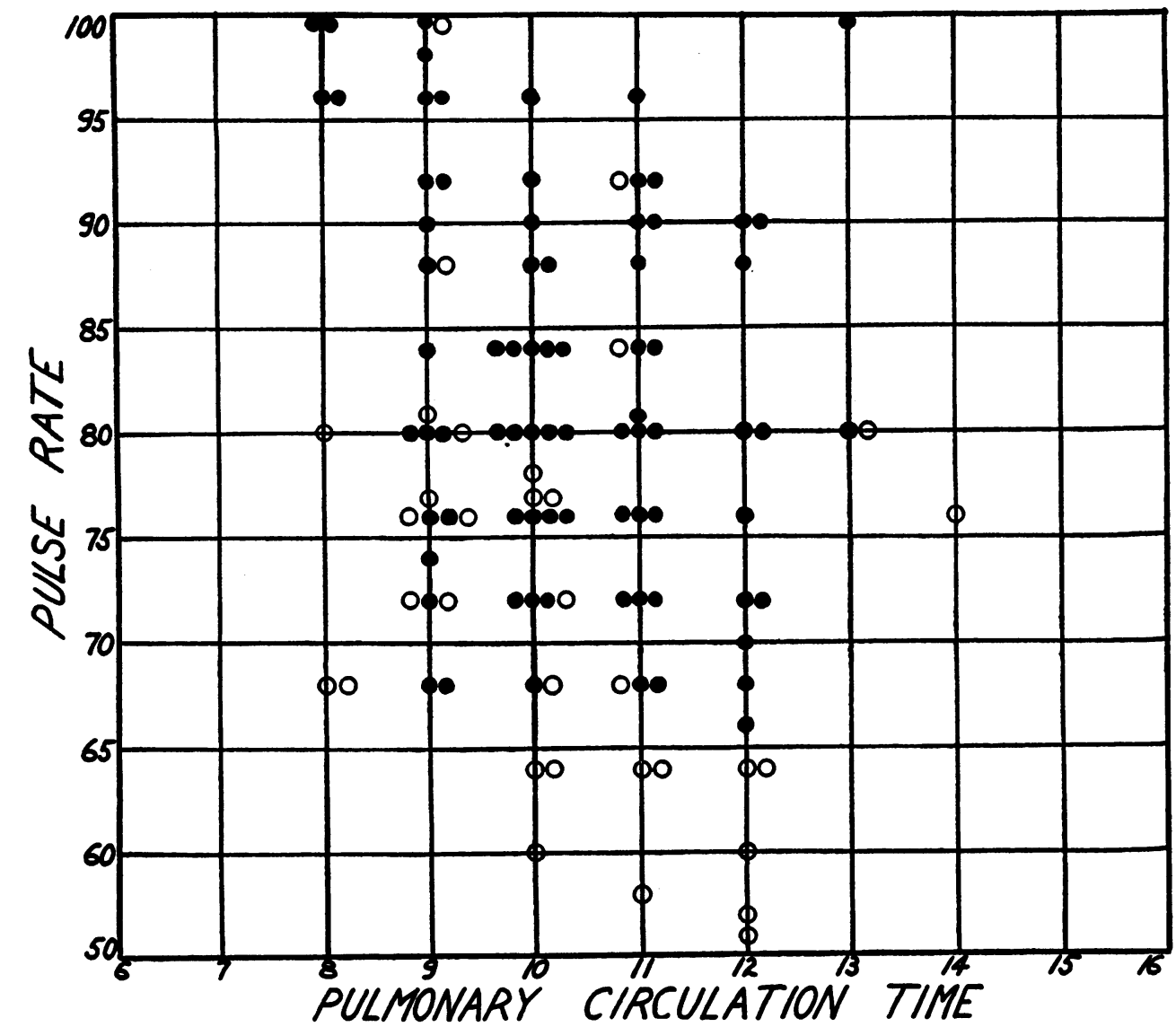

Fig. 5. The Relationship Between the Pulse Rate and the Pulmonary Circulation Time.

The solid dots represent individual ante partum observations, the circles represent individual postpartum observations.

obesity was present, since it is high in obesity $(43,44)$. In Cases N36 and N38 the postpartum values were higher than the ante partum values. ${ }^{2}$

\section{Vital capacity}

One hundred and fifty-two determinations of the vital capacity were made on 37 normal pregnant women; 108 before and 44 after delivery. The values in most instances were within the limits set as normal for non-pregnant women, i.e., $2000 \mathrm{cc}$. per square meter body surface area (45, 46). Thirty-four of the 37 had vital capacities of at least 90 per cent of normal and 36 at least 85 per

\footnotetext{
2 Further observations on the venous pressure in pregnancy will appear in a subsequent communication.
}

cent of normal, only one (Case N31) falling below 85 per cent. In this patient it was 74 per cent of normal at its lowest level in the 24th week and 88 per cent at its highest in the 36th week. During postpartum observations on this patient, made at $2,6,26$ and 65 weeks after delivery, the vital capacity never exceeded its highest pregnancy level of 88 per cent of normal. It is sufficient to note here ${ }^{3}$ that the vital capacity either remained constant or rose during the course of pregnancy in the majority of the patients in this group; in a few there was a slight decrease as pregnancy progressed.

\footnotetext{
3 Further discussion of the observations on the vital capacity in pregnancy will appear in a subsequent paper.
} 


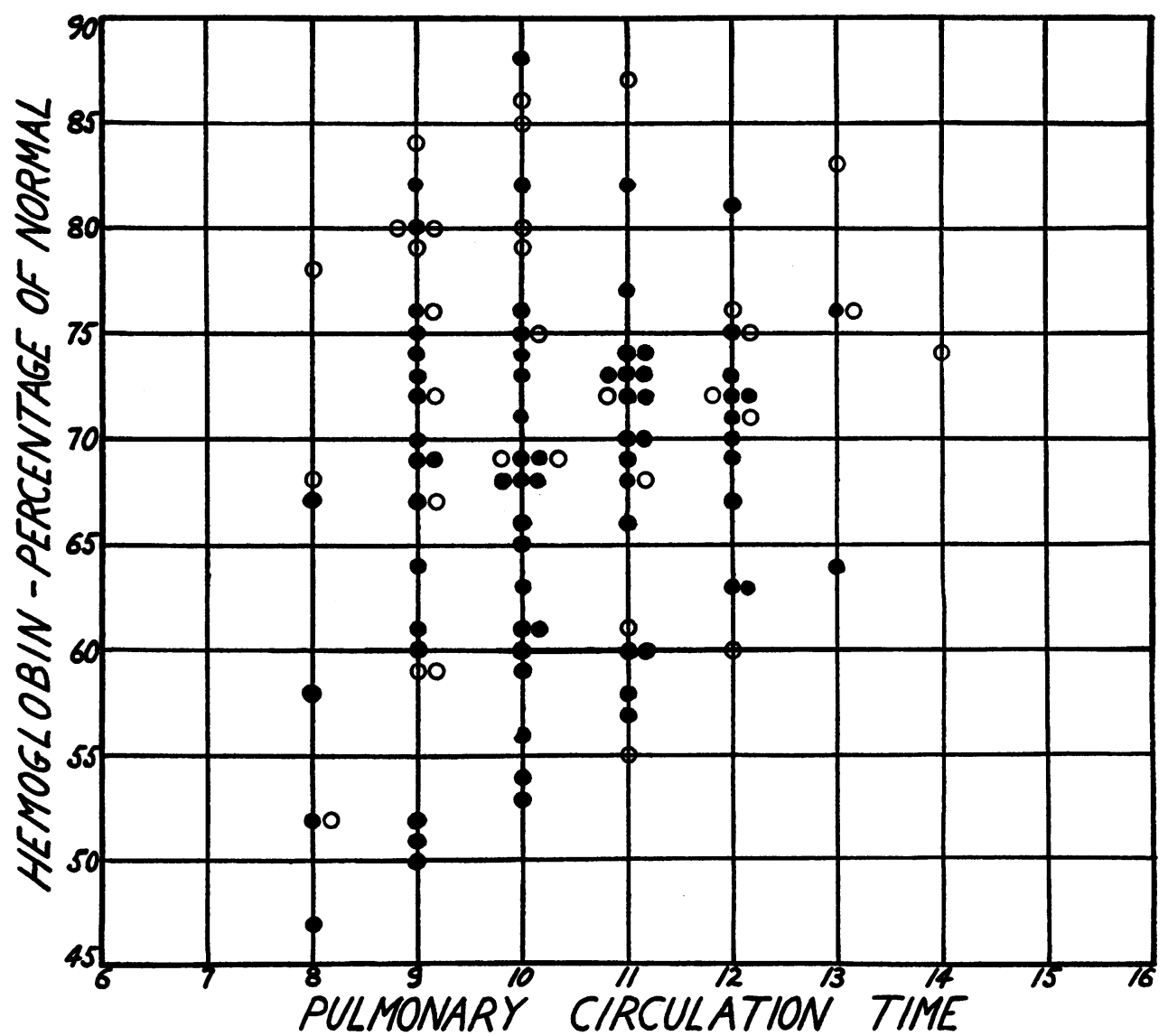

Fig. 6. The Relationship Between the Hemoglobin and the Pulmonary Circulation. Time.

The solid dots represent individual ante partum observations, the circles represent individual postpartum observations.

\section{Subcostal angle}

In all but 2 patients (Cases N25 and N30), in whom the subcostal angle was measured with a protractor, there was an increase as pregnancy progressed with a decrease after delivery (Table I). The maximum increase observed during pregnancy was $44^{\circ}$.

\section{Blood pressure}

The basal arterial blood pressure (Table I) was within the limits set as normal for pregnant women (47) except for 2 cases (Case N2O at 2 weeks postpartum and Case N16 at 38 weeks pregnant).

\section{Pulse rate}

The pulse rate ante partum (Table I) under basal conditions varied from 60 to 100 beats per minute (average 80.6 beats). Postpartum, it varied between 52 and 92 (average 70 beats).

\section{Respiratory rate}

The basal respiratory rate (Table I), ante partum, varied between 10 and 28 per minute (average 18.0 per minute). Postpartum, the variation was between 10 and 28 (average 17.5).

\section{Blood}

Hemoglobin determinations and hematocrit readings were carried out at frequent intervals, before and after delivery (Table I). In every subject observed two or more times during gestation there was a fall in the hemoglobin, as pregnancy progressed. This change was usually accompanied by a fall in the hematocrit reading. 


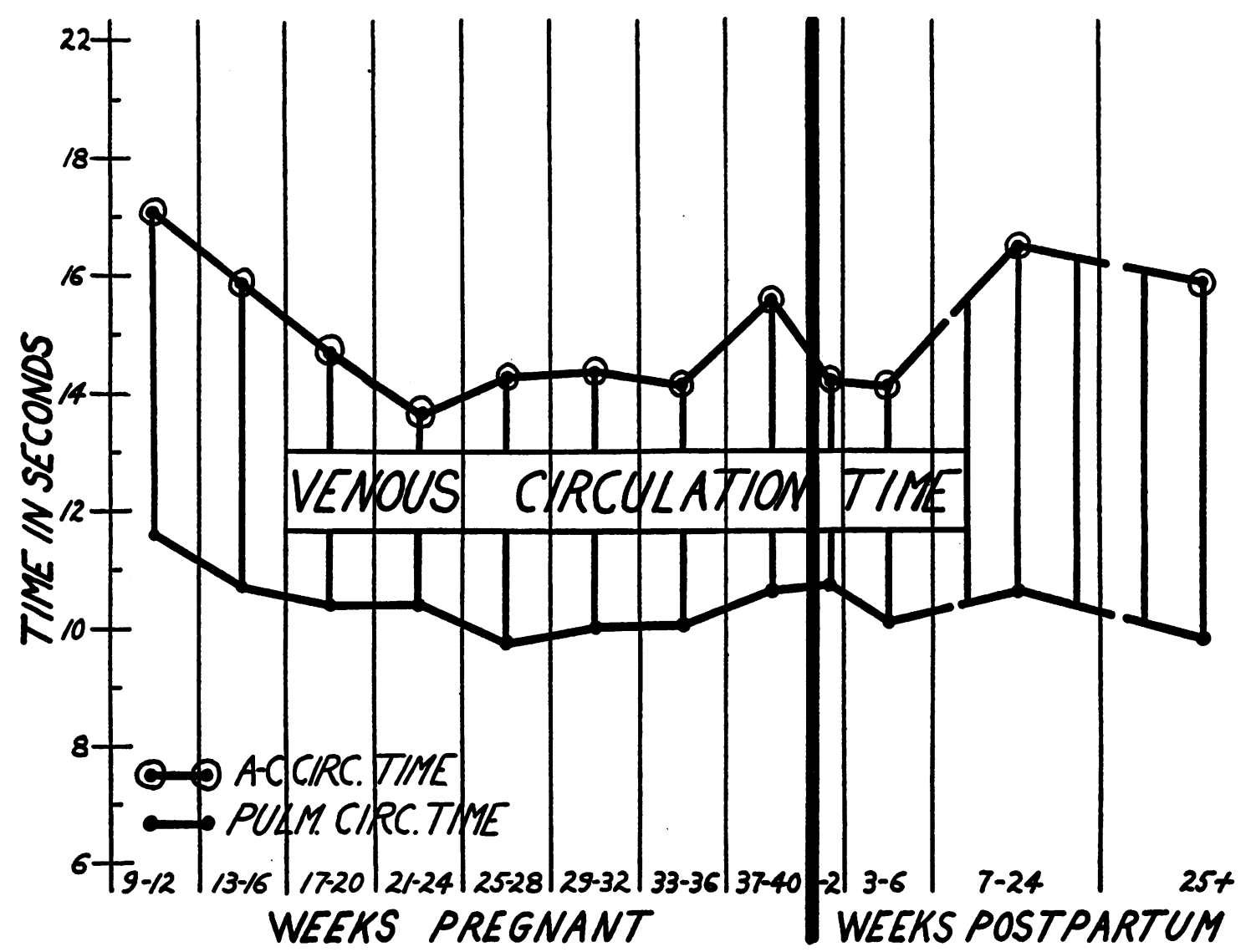

Fig. 7. The Venous Circulation Time in Normal Pregnant Women.

The upper curve represents the average arm to carotid circulation time; the lower curve represents the average pulmonary circulation time; the shaded area between represents the average venous circulation time. The heavy perpendicular line represents delivery and separates the ante and postpartum periods.

During the latter weeks there was a tendency for both measurements to rise (Figure 8 ). This observation is in accord with that of Kühnel (5). Of 15 patients, 10 showed an increase in the postpartum hemoglobin value; 5 showed a decrease. Of 18 patients, the hemoglobin rose in 14 by the 7 th week postpartum; 4 showed a decrease.

\section{DISCUSSION}

\section{Method}

The cyanide method proved to be practical for studying the velocity of blood flow in pregnant women. Sodium cyanide, in the doses reported here, can be administered to pregnant women without harm to either mother or child. Early in the study, the fetal heart was examined with the fetoscope during and after the administration of cyanide and no apparent change in rate or rhythm was noted. No ill effects to the baby were demonstrable at birth or afterwards. There was one fetal death but it was clearly unrelated to the administration of cyanide. (Table I, Case 30 . The last dose of cyanide was given one month before delivery. The baby died 18 hours after delivery of respiratory failure. The autopsy showed intracranial hemorrhage and pulmonary atelectasis.)

An occasional patient, usually one to whom a relatively large dose of cyanide was given, showed, after the respiratory response, flickering of the eyelids. Rarely, coincident with this, there was a period during which the patient could not speak for a few moments but could comprehend and execute physical commands. Such reactions were of short duration and did not prevent further tests. Antidotes against cyanide, namely, amyl 


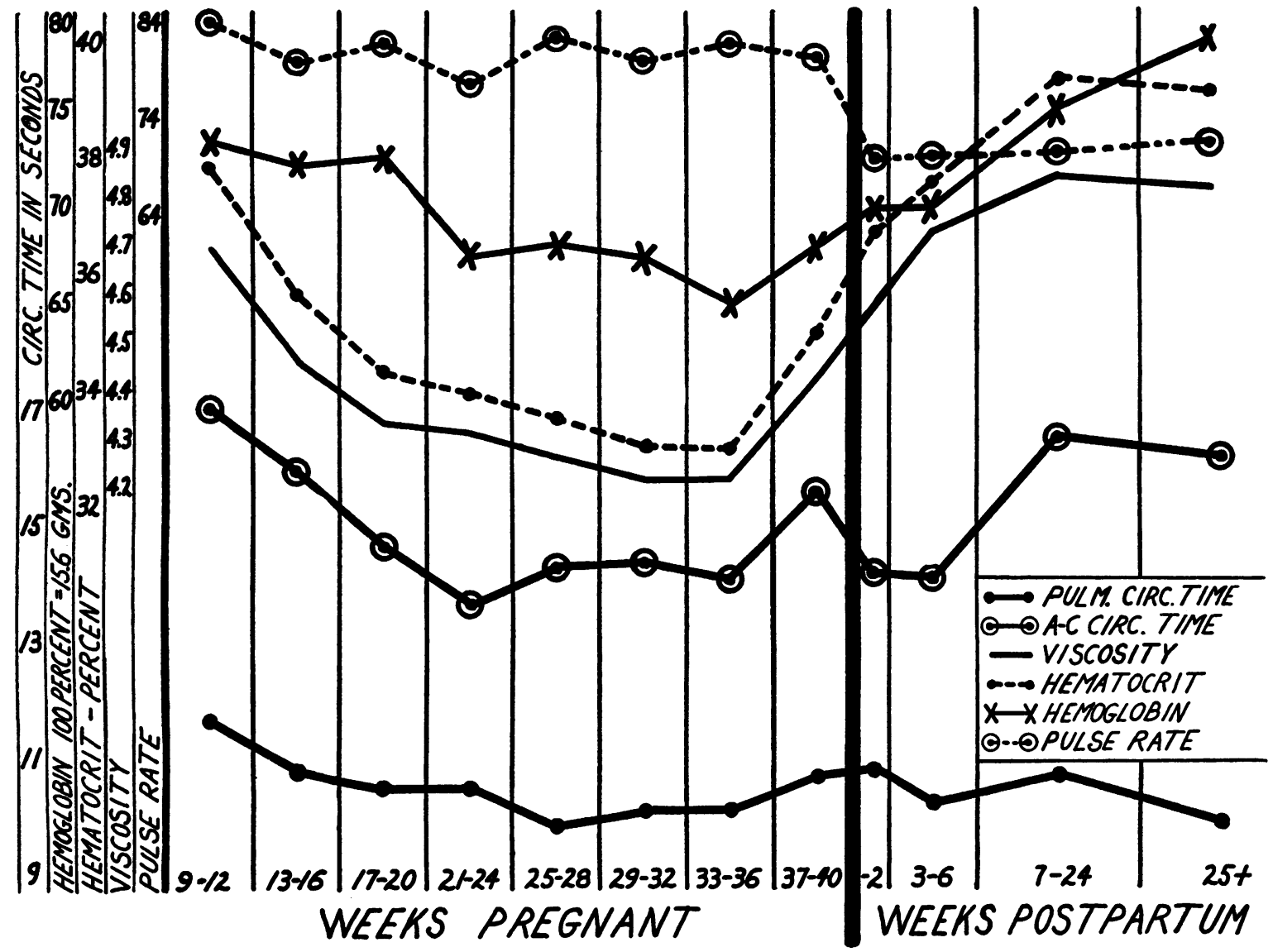

Fig. 8. The Relationship Between the Average Arm to Carotid and Pulmonary Circulation Times and the Average Viscosity of the Blood, the Average Hematocrit, the Average Hemoglobin and the Average Pulse Rate in 37 Normal Pregnant Women.

The heavy perpendicular line represents delivery and separates the ante and postpartum periods. For numerical values see Table II.

nitrite, sodium nitrite, sodium thiosulphate and methylene blue (48), were always at hand but it was never necessary to use them.

The decholin method of Winternitz, Deutsch and Brüll (27), as modified by Gargill (34), was used in a few patients. Because, in some there was vomiting and in others the response was not definite or consistent, perhaps due to the raising, by 60 per cent, of the threshold for bitter taste in pregnancy described by Hansen and Langer (49), this method was not felt to be as satisfactory as the cyanide method.

For pregnant women the effective dose of sodium cyanide was less per kilogram of body weight than that used in normal non-pregnant subjects (28). The increase in the weight of the mother caused by pregnancy might cause a relative decrease in dosage; but this explanation is probably incorrect because the dose required is usually greater after delivery than before. The smaller dose might reflect an increased sensitivity of the carotid sinus in pregnancy.

\section{Results}

The values for the A-C circulation time in normal pregnancy fall almost without exception within the normal non-pregnant limits of 9 to 21 seconds (28). From the 17 th, through the 36th week of gestation, there seems to be a definite decrease in the average A-C circulation time. The diminished arteriovenous oxygen difference in pregnancy, and the lag in oxygen consumption 
as compared with the cardiac output, demonstrated by Burwell and Strayhorn (8), are additional evidence that the circulation is speeded during pregnancy.

In the last 4 weeks ( 37 th to 40 th) there is an apparent increase in the $\mathrm{A}-\mathrm{C}$ circulation time as compared with the preceding weeks. The number of observations in the 37 th to 40 th week period presented here is not sufficient to establish this point. The fact that the pulmonary circulation shows a parallel, though slight, rise during the same period, and the observation that a group of 33 pregnant women with compensated heart disease (50) shows a similar change in the last 4 weeks of pregnancy, are, however, further corroborative evidence. Burwell and Strayhorn (8) have shown, furthermore, that the cardiac output increases during pregnancy but that during the last weeks it is less than in the preceding months. Gammeltoft $(10,11)$ found a similar change. This change is corroborative evidence that the A-C circulation time is increased in the 37 th to 40th week period, if the assumption is correct that, other factors remaining equal, the speed of the circulation varies directly with the cardiac output (51).

Following delivery there is again a decrease of the A-C circulation time, which seems to persist for several weeks after delivery (Figure 1). Further evidence that the circulation is speeded immediately postpartum and for some time afterwards, is given by Gammeltoft $(10,11)$ and Haupt (13), who showed that the cardiac output, although less postpartum than ante partum, did not return to the normal non-pregnant level for several weeks (as long as 4 months in 1 patient of Gammeltoft) after parturition. From the observations presented here, it appears that the A-C circulation time returns to normal certainly by the sixth month postpartum and probably earlier.

The explanation of the decrease in the circulation time during pregnancy and early in the puerperium (to the 7th week) is not clear. The various factors known to affect the velocity of blood flow in non-pregnant individuals should be considered.

Anemia in non-pregnant individuals has been reported to cause a decrease in the pulmonary, arm to arm, and arm to tongue circulation times
$(22,30,34)$ and histamine reaction time (35). In most of the patients in this series a fall in hemoglobin and hematocrit values typical of pregnancy was observed (5). There seems to be no apparent correlation, however, between the per cent of hemoglobin and the $\mathrm{A}-\mathrm{C}$ circulation time when these two factors are plotted against each other (Figure 3). Neither is there any apparent correlation between the individual hematocrit readings and $\mathrm{A}-\mathrm{C}$ circulation time. Yet, when the average values for hemoglobin and hematocrit readings are plotted, the resultant curves are similar to the course of the average A-C circulation time during pregnancy (Figure 8). Immediately after delivery and up to the 7 th week postpartum this apparent similarity is absent.

A decrease in the pulmonary, arm to arm, and arm to tongue circulation times $(22,25,34,36)$ and histamine reaction time (35) has been reported in non-pregnant cases of hyperthyroidism. It has also been reported that the basal metabolic rate is increased in pregnancy $(15,52,53,54)$. This might account for the decreased circulation time demonstrated in this series. The occasional measurements of basal metabolic rate, while not sufficient in number to be conclusive, were within normal limits, however, in spite of the decreased circulation time. The postpartum decrease in the A-C circulation time observed is probably not due to increase in the basal metabolic rate, since this and oxygen consumption are reported to return to normal within a few days postpartum $(15,16,53)$, while the cardiac output and velocity of blood flow do not for several weeks at least $(10,11,13)$.

The pulse rate is elevated during pregnancy and drops on the average about 10 beats per minute (Table II) after delivery. There seems to be no correlation, however, between the A-C circulation time and pulse rate as regards either individual observations (Figure 2) or average values (Figure 8 ).

There is an increased cardiac output during pregnancy $(8,9,10,11,12,13)$ which might contribute to the decrease in the A-C circulation time or might be dependent upon it. Further study is necessary to elucidate this point.

It. was shown by Esiaschwili (55) that the viscosity of the blood is decreased in pregnancy 
up to the sixth month, is slightly increased in the seventh month, is unknown in the latter months, and presents a consistent postpartum rise. It is known that the speed of flow of a liquid varies inversely with its viscosity (Poiseuille's law). Lowered blood viscosity would result accordingly in increased velocity of blood flow.

Nygaard, Wilder and Berkson (56) showed that the relation of the viscosity of whole blood to the hematocrit readings may be expressed by the linear equation $V_{w b}=0.978+0.098 H$, where $V_{w b}=$ the viscosity of whole blood and $H$ $=$ hematocrit reading in per cent (this relationship holds only when the hematocrit reading ranges between 15 to 50 per cent).

The average viscosity was calculated, from this equation, for the various periods of pregnancy and the puerperium. There is a steady decrease to the 37 to 40th week period (Table II) when an increase occurs and continues on through the postpartum period.

When the average viscosity values are plotted with the average values of the $\mathrm{A}-\mathrm{C}$ circulation time there is a similarity in the curves (Figure 8) which suggests that there is a definite relationship between the blood viscosity and the velocity of blood flow. Immediately after delivery, however, and up to the 7th week postpartum this apparent similarity is lacking. Although the complex bodily readjustments which occur during this time (from delivery to the 7 th postpartum week), make a simple explanation of the speeding of the A-C circulation difficult, it seems possible that lactation, with its concomitant physiological changes, is an important factor.

From the preceding discussion it is evident that there are several factors which might produce the acceleration of the circulation in pregnancy. The decrease in the viscosity of the circulating blood would seem to be one of the most important since the changes in the velocity of blood flow which occur simultaneously with, or are dependent upon it, coincide with Poiseuille's law.

The results presented here seem at first glance to disagree with the work of Klee (38) who found a slowing in the rate of flow of the circulation in pregnancy. However, the fluorescein method of Koch (37) which he used, necessitates that the test substance traverse the peripheral capillary circulation, which in the measurements of the A-C circulation by the cyanide method is not the case. Since the velocity of the circulation is reported as slowed in the capillaries in normal pregnancy $(38,57)$ there need be no contradiction in the results. Klee also reported a difference between primiparae and multiparae but since only single observations during the last three months of pregnancy were made his results are difficult to evaluate. Such a difference was not demonstrated in this series.

In a study by Spitzer of the circulation time in pregnancy, the use of the decholin method indicated no difference in the arm to tongue pathway between normal non-pregnant and pregnant women. In that study single observations were made on 27 normal patients, all in the last three months of pregnancy. This fact, plus the possible effect of the altered sensibility of the tongue in pregnancy (49) make the results from that study difficult to compare with those obtained by the cyanide method.

The values for pulmonary circulation time fall, without exception, within the normal non-pregnant limits of 7 to 14 seconds. Its curve follows quite closely that of the average A-C time (Figures $4,7,8)$, although the changes are slight. Between it and the pulse rate and hemoglobin (individual observations) no evident correlation exists (Figures 5 and 6). X-ray photographs of the lungs during normal pregnancy show an increase in the pulmonary markings (58) which might be interpreted as being due to increase in the size of the capillary bed. If this is true, it would account for the relatively slight increase in the velocity of the pulmonary blood flow as contrasted with that observed in the A-C pathway. It would also account for the increase in total amount of blood flowing through the lungs, coincident with the increase in cardiac output, without an increase in the velocity of pulmonary flow.

Since the pulmonary circulation time shows but slight change throughout pregnancy and the puerperium, the venous circulation time follows the changes observed in the $\mathrm{A}-\mathrm{C}$ time and the factors influencing it are the same as those discussed in relation to the A-C circulation time. The speeding of the circulation apparently occurs in this component of the circulatory pathway and not in the pulmonary circuit. 
The vital capacity, blood pressure, pulse rate, respiratory rate, venous pressure, and subcostal angle showed no apparent relationship to the changes observed in the circulation time and need not be discussed here.

Neither dyspnea or edema bore any constant relationship to the changes in the velocity of blood flow (Table I).

\section{CONCLUSIONS}

1. The arm to carotid, pulmonary and venous circulation times can be studied safely in pregnancy by the cyanide method.

2. The values for the arm to carotid, pulmonary and venous circulation times fall within the normal non-pregnant range.

3. There is a decrease in the average arm to carotid circulation time from the 17 th to the 36 th week of pregnancy, inclusive.

4. There is probably an increase in the average arm to carotid circulation time, relative to the 17 th to 36 th week period, in the period from the 37 th to the 40 th week.

5. There is a decrease in the average arm to carotid circulation time following delivery which persists until the 7 th postpartum week; after which the arm to carotid circulation time returns to the normal non-pregnant level.

6. There is little change in the pulmonary circulation time during pregnancy, although the trend is the same as that of the arm to carotid circulation time.

7. The speeding of the circulation in pregnancy seems to occur in the peripheral venous component of the vascular system.

8. Various factors that might decrease the circulation time in pregnancy are discussed, and, of them, the decreased viscosity of the blood is considered the most probable important contributing factor.

The authors are indebted to Doctors Geo. P. Robb and Duncan E. Reid for assistance in part of this work and to Dr. E. B. Wilson, statistician, for reviewing the charts and data.

\section{BIBLIOGRAPHY}

1. Gassner, U. K., Veränderungen des Körpergewichtes bei Schwangeren, Gebärenden und Wöcherinnen. A. Th. Engelhardt, Leipzig, 1861.

2. Zangemeister, W., Der Hydrops gravidarum sein Verlauf und seine Beziehungen zur Nephropathie und Eklampsie. Ztschr. f. Geburtsh. u. Gynäk., 1919, 81, 491.

3. Davis, C. H., Weight in pregnancy. Its value as a routine test. Am. J. Obst. and Gynec., 1923, 6, 575.

4. Kerwin, W., Weight estimates during pregnancy and the puerperium. Am. J. Obst. and Gynec., 1926, 11, 473.

5. Kühnel, P., Untersuchungen über die physiologische Schwangerschaftsanämie. Ztschr. f. Geburtsh. u. Gynäk., 1927, 90, 511.

6. Galloway, C. E., Anemia of pregnancy. J. A. M. A., 1929, 93, 1695.

7. Strauss, M. B., and Castle, W. B., Studies of anemia in pregnancy. II. The relationship of dietary deficiency and gastric secretion to blood formation during pregnancy. Am. J. M. Sc., 1932, 184, 663.

8. Burwell, C. S., and Strayhorn, W. D., Observations on the circulation during and after pregnancy. $J$. Clin. Invest. (Proc.), 1933, 12, 977.

9. Stander, H. J., and Cadden, J. F., The cardiac output in pregnant women. Am. J. Obst. and Gynec., 1932, 24, 13.

10. Gammeltoft, S. A., Recherches sur le débit cardiaque par minute pendant la grossesse. Compt. rend. Soc. de biol., 1926, 94, 1099.

11. Gammeltoft, S. A., The heart in pregnancy. Surg., Gynec., and Obst., 1928, 46, 382.

12. Schmidt, R. H., Über die Herzarbeit in der Frühschwangerschaft in der Ruhe und nach Arbeitsversuchen. Monatschr. f. Geburtsh. u. Gynäk., 1932, 90, 83.

13. Haupt, W., Vergleichende Kreislaufuntersuchungen bei gesunden Schwangeren und Wöchnerinnen. Ztschr. f. Geburtsh. u. Gynäk., 1927, 91, 577.

14. Magnus-Levy, Stoffwechsel und Nahrungsbedarf in der Schwangerschaft. Ztschr. f. Geburtsh. u. Gynäk., 1904, 52, 116.

15. Root, H. F., and Root, H. K., The basal metabolism during pregnancy and the puerperium. Arch. Int. Med., 1923, 32, 411.

16. Rowe, A. W., Alcott, M. D., and Mortimer, E., The metabolism in pregnancy. II. Changes in the basal metabolic rate. Am. J. Physiol., 1925, 71, 667.

17. Sandiford, I., and Wheeler, T., The basal metabolism before, during, and after pregnancy. J. Biol. Chem., 1924, 62, 329.

18. Miller, J. R., Keith, N. M., and Rowntree, L. E., Plasma and blood volume in pregnancy. J. A. M. A., 1915, 65, 779.

19. Neubauer, W., Blutmengenbestimmung vor, während und nach der Geburt. Deutsche med. Wchnschr., 1923, 49, 520.

20. Dieckmann, W. J., and Wegner, C. R., The blood in normal pregnancy. I. Blood and plasma volumes. Arch. Int. Med., 1934, 53, 71.

21. Corwin, J., Herrick, W. W., Valentine, M., and Wilson, J. M., Pregnancy and heart disease. A statistical report and summary of 196 cases. Am. J. Obst. and Gynec., 1927, 13, 617. 
22. Blumgart, H. L., The velocity of blood flow in health and disease. Medicine, 1931, 10, 1.

23. Blumgart, H. L., and Weiss, S., Studies on the velocity of blood flow. II. The velocity of blood flow in normal resting individuals and a critique of the method used. J. Clin. Invest., 1927, 4, 15.

24. Blumgart, H. L., and Weiss, S., Studies on the velocity of blood flow. VII. The pulmonary circulation time in normal resting individuals. J. Clin. Invest., 1927, 4, 399.

25. Blumgart, H. L., Gargill, S. L., and Gilligan, D. R., Studies on the velocity of blood flow. XIII. The circulatory response to thyrotoxicosis. J. Clin. Invest., 1930, 9, 69.

26. Blumgart, H. L., and Weiss, S., Clinical studies on the velocity of blood flow. IX. The pulmonary circulation time, the velocity of venous blood to the heart, and related aspects of the circulation in patients with cardiovascular disease. J. Clin. Invest., 1928, 5, 343.

27. Winternitz, M., Deutsch, J., and Brüll, Z., Eine klinisch brauchbare Bestimmungsmethode der Blutumlaufszeit mittels Decholininjektion. Med. Klin., 1931, 27, 986.

28. Robb, G. P., and Weiss, S., A method for the measurement of the velocity of the pulmonary and peripheral venous blood flow in man. Am. Heart J., 1933, 8, 650.

29. Robb, G. P., and Weiss, S., The velocity of pulmonary and peripheral venous blood flow and related aspects of the circulation in cardiovascular disease. Their relation to clinical types of circulatory failure. Am. Heart J., 1934, 9, 742.

30. Blumgart, H. L., Gargill, S. L., and Gilligan, D. R., Studies on the velocity of blood flow. XV. The velocity of blood flow and other aspects of the circulation in patients with "primary" and secondary anemia and in two patients with polycythemia vera. J. Clin. Invest., 1931, 9, 679.

31. Blumgart, H. L., and Weiss, S., Studies on the velocity of blood flow. IV. The velocity of blood flow and its relation to other aspects of the circulation in patients with arteriosclerosis and in patients with arterial hypertension. J. Clin. Invest., 1927, 4, 173.

32. Weiss, S., and Blumgart, H. L., Studies on the velocity of blood flow. VIII. The velocity of blood flow and its relation to other aspects of the circulation in patients with pulmonary emphysema. J. Clin. Invest., 1927, 4, 555.

33. Blumgart, H. L., and Weiss, S., Studies on the velocity of blood flow. III. The velocity of blood flow and its relation to other aspects of the circulation in patients with rheumatic and syphilitic heart disease. J. Clin. Invest., 1927, 4, 149.

34. Gargill, S. L., The use of sodium dehydrocholate as a clinical test of the velocity of blood flow. New England J. Med., 1933, 209, 1089.
35. Weiss, S., Robb, G. P., and Blumgart, H. L., The velocity of blood flow in health and disease as measured by the effect of histamine on the minute vessels. Am. Heart J., 1929, 4, 664.

36. Blumgart, H. L., Gargill, S. L., and Gilligan, D. R., Studies on the velocity of blood flow. XIV. The circulation in myxedema with a comparison of the velocity of blood flow in myxedema and thyrotoxicosis. J. Clin. Invest., 1930, 9, 91.

37. Koch, E., Die Stromgeschwindigkeit des Blutes. Deutsches Arch. f. klin. Med., 1922, 140, 39.

38. Klee, F., Die Strömungsgeschwindigkeit des Blutes in der Schwangerschaft. Ztschr. f. Geburtsh. u. Gynäk., 1924, 88, 308.

39. Spitzer, W., Die Blutströmungsgeschwindigkeit in normaler und gestörter Schwangerschaft. Beitrag zur Funktionsprüfung des Herzens in der Schwangerschaft und vor der Geburt. Arch. f. Gynäk., 1933, 154, 449.

40. Moritz, F., and von Tabora, D., Uber eine Methode, beim Menschen den Druck in oberflächlichen Venen exakt zu bestimmen. Deutsches Arch. f. klin. Med., 1910, 98, 475.

41. Dubois, D., and DuBois, E. F., Clinical calorimetry. $\mathrm{X}$. A formula to estimate the approximate surface area if height and weight be known. Arch. Int. Med., 1916, 17, 863.

42. Wintrobe, M. M., Macroscopic examination of the blood. Discussion of its value and a description of the use of a single instrument for the determination of sedimentation rate, volume of packed red cells, leukocytes and platelets and of icterus index. Am. J. M. Sc., 1933, 185, 58.

43. Rotky, H., and Klein, O., Studien über Venendruck und Kreislaufsuffizienzprüfung nach $\mathrm{E}$. Weiss nebst einem Beitrag über die Ursachen der Steigerung des Venendrucks bei Hypertonikern. Med. Klin., 1923, 19, 1542.

44. Kroetz, C., Die Koeffizienten des klinisch messbaren Venendruckes. Deutsches Arch. f. klin. Med., 1922, 139, 325.

45. Christie, C. D., and Beams, A. J., The estimation of normal vital capacity with special reference to the effect of posture. Arch. Int. Med., 1922, 30, 34.

46. West, H. F., Clinical studies on the respiration. VI. A comparison of various standards for the normal vital capacity of the lungs. Arch. Int. Med., 1920, $25,306$.

47. Irving, F. C., The systolic blood pressure in pregnancy. Observations on 5000 consecutive cases in the pregnancy clinic of the Boston Lying-in Hospital. J. A. M. A., 1916, 66, 935.

48. Hanzlik, P. J., and Richardson, A. P., Cyanide antidotes. J. A. M. A., 1934, 102, 1740.

49. Hansen, R., and Langer, W., Uber Geschmacksveränderungen in der Schwangerschaft. Klin. Wchnschr., 1935, 14, 1173.

50. Cohen, M. E., and Thomson, K. J., Unpublished data. 
51. Grollman, A., The Cardiac Output of Man in Health and Disease. Chas. C. Thomas, Springfield, 1932.

52. Cornell, E. L., Metabolism readings in 84 pregnant cases. Surg., Gynec., and Obst., 1923, 36, 53.

53. Plass, E. D., and Yoakam, W. A., Basal metabolism studies in normal pregnant women with normal and pathologic thyroid glands. Am. J. Obst. and Gynec., 1929, 18, 556.

54. Stander, H. J., and Peckham, C. H., Basal metabolism in the toxemias of pregnancy. Bull. Johns Hopkins Hosp., 1926, 38, 227.
55. Esiaschwili, I., Blutgerinnung und Viskosität in der Schwangerschafts und Nachgeburtsperiode. Zentralbl. f. Gynäk., 1933, 57, 2717.

56. Nygaard, K. K., Wilder, M., and Berkson, J., The relation between the viscosity of the blood and the relative volume of erythrocytes (hematocrit value). Am. J. Physiol., 1935, 114, 128.

57. Hinselmann, H., Nettekoven, H., and Silberbach, W., Die Capillarströmung bei der Eklampsie. Arch. f. Gynäk., 1923, 116, 443.

58. Robbins, S. A., Personal communication. 